\title{
Desrespeito e luta por reconhecimento
}

\author{
Disrespect and struggle for recognition
}

\begin{abstract}
Emil A. Sobottka*
Resumo: O texto coloca em discussão a questão se a teoria do reconhecimento, de Axel Honneth, formulada em e com referência unicamente a sociedades economicamente centrais no capitalismo atual, pode servir de referência para pesquisas em contextos distantes e distintos daquela sua origem. A referência empírica é uma pesquisa em contexto de periferia suburbana, feita com mulheres engajadas em uma política pública de segurança e cidadania. Além de observação participante e grupos focais, a metodologia incluiu entrevistas similares às narrativas biográficas. A entrevista iniciava com a solicitação de que a interlocutora contasse livremente "um pouco da história de sua vida". O foco concreto neste texto diz respeito ao potencial do sofrimento para desencadear - ou não - de lutas por reconhecimento face a situações agudas de desrespeito. Estas situações são retratadas exemplarmente através de um extrato de uma destas narrativas.
\end{abstract}

Palavras-chave: Mulheres. Sofrimento. Movimentos sociais. Cidadania. Reconhecimento. Desrespeito.

\begin{abstract}
The paper discusses the question if the theory of recognition of Axel Honneth, formulated in and with reference only to economically central societies in contemporary capitalism, can serve as a reference for research in contexts geographically remote and socially distinct from that original one. The empirical reference is a research in a suburban peripheric context in Brazil, involving women engaged in a public policy on security and citizenship. In addition to participant observation and focus groups, the methodology included interviews similar to the biographical narratives. The interviews began with a request to freely tell "a little about the history of your life." The particular focus in this paper concerns the potentials of suffering to stimulate struggles for recognition considering the acute situations of disrespect. These situations are exemplarily depicted by an extract of one of these narratives.
\end{abstract}

Keywords: Women. Disrespect. Suffering. Social movements. Citizenship. Recognition.

\footnotetext{
* Doutor em Sociologia e Ciência Política pela Universidade de Münster (WWU-Münster, Alemanha), professor no PPG de Ciências Sociais da Pucrs em Porto Alegre, RS, Brasil, Secretário Executivo da Sociedade Brasileira de Sociologia, pesquisador do CNPq e editor da Civitas: Revista de Ciências Sociais< <sobottka@pucrs.br>.
}

Civitas, Porto Alegre, v. 15 , n. 4, p. 686-702, out.-dez. 2015 
A teoria do reconhecimento, especialmente tal como vem sendo formulada por Axel Honneth, quando faz referência a contextos empíricos toma como perspectiva as sociedades industrializadas, especialmente as da Europa e os Estados Unidos. Ela não tem incluído em seu horizonte experiências de outros contextos geográficos e culturais. Face a esse limitado escopo de referência, é possível colocar a questão se ela pode referenciar pesquisas em situações sociais muito distintas e distantes de sua origem. No presente texto pretendo fazer uma tentativa de dialogar com aquela teoria em uma pesquisa na periferia suburbana, tendo como foco concreto a questão do desencadeamento de lutas por reconhecimento.

No seu livro seminal sobre esta teoria, Honneth (2003a) sugeriu reiteradamente que a percepção de ter sido injustiçado seria o principal estopim da luta por reconhecimento. Em sua discussão com Nancy Fraser (Honneth, 2003 b), ele é inclusive explícito e enfático nessa tese, mesmo ressalvando que nem toda indignação moral leva a uma resistência ativa. Esta conexão entre desrespeito sofrido, indignação moral e resistência ativa esteve em foco na situação pesquisada.

A base empírica para o texto é constituída por uma pesquisa feita com mulheres envolvidas no Programa Nacional de Segurança Pública com Cidadania (Pronasci), especificamente em projetos Mulheres da Paz, em contextos de pobreza e violência na região metropolitana de Porto Alegre. Além de pesquisa participante e grupos focais, para coletar os dados os membros da equipe de pesquisa ${ }^{1}$ valeram-se de um tipo específico de entrevistas, similar a narrativas biográficas (Rosenthal, 2014): solicitaram às mulheres participantes que contassem um pouco sobre a história de suas vidas. As entrevistadas podiam escolher livremente o enquadramento no tempo, os temas e o tamanho de sua fala. Depois da fala inicial, que podia durar uns poucos minutos ou bem mais de uma hora, seguiam-se perguntas que retomavam temas referidos pela entrevistada, com o intuito de aprofundá-los um pouco mais.

As narrativas invariavelmente revelavam experiências de desrespeito à integridade do corpo, e vinham acompanhadas da convicção dessas mulheres, de terem sido moralmente injuriadas. Mas o transcurso da entrevista revelava que esta consciência da injuria raramente mobilizou a indignação em direção a reações consistentes tais como resistência ou uma luta coletiva por reconhecimento junto com as outras pessoas que sofriam a mesma humilhação. Foi essa distância entre o que sugeria a teoria do reco-

\footnotetext{
${ }^{1}$ Participaram nesta etapa Maria Eduarda Ota, João Carlos Bassani, Guido José Rey Alt, Ismael Possobon Dias e Alexandre Kunsler, com apoio da Fapergs e do CNPq.
} 
nhecimento e as constatações empíricas em campo que motivaram a reflexão aqui exposta.

Desde seus inícios, a Teoria Crítica em suas diferentes versões toma como um horizonte normativo a reivindicação moderna da constituição de sujeitos autônomos, capazes de desenvolverem e de realizarem projetos para suas próprias vidas e, no limite, projetos de sociedade em forma de utopias concretas (Sobottka, 2008). Para a primeira geração desta escola teórica, os indivíduos eram, eles próprios, responsáveis por desenvolverem a necessária consciência e por tomarem a decisão sobre como atualizar, no sentido práticoefetivo, esses projetos em cada situação concreta. Depois que Karl-Otto Apel e em especial Jürgen Habermas (1988) impulsionaram a virada linguística na filosofia e nas ciências sociais, a intersubjetividade passou a ser, nesta orientação teórica, um pressuposto antropológico amplamente aceito. Com esse pressuposto, as relações sociais recebem um lugar central e, até certo ponto, determinante em toda a teoria social crítica. Para levar esta mudança a sério, a pesquisa empírica necessita recuperar o lugar de destaque que Horkheimer havia previsto originalmente para o trabalho multidisciplinar (Sobottka, 2008). Mas antes de apresentar e discutir alguns resultados empíricos, será necessário aclarar o marco teórico em que a discussão se insere.

\section{Relações sociais de reconhecimento e o desenvolvimento de autorrelações práticas}

Axel Honneth desenvolve sua contribuição para a Teoria Crítica colocando a questão do reconhecimento no centro da reflexão. Ele assume como dada uma premissa antropológica segundo a qual "os seres humanos são vulneráveis naquela maneira específica que denominamos 'moral' porque eles devem sua identidade à construção de uma autorrelação prática que desde o início depende da ajuda e da afirmação de outros seres humanos" (Honneth, 2007, p. 137). Muito distante da concepção kantiana do sujeito auto-emancipado, aqui as relações intersubjetivas são tidas como constitutivas na medida em que "os sujeitos humanos somente podem desenvolver uma autorrelação intacta quando verem-se afirmados ou reconhecidos de acordo com o valor de certas capacidades e direitos" (ibid., p. 138).

As relações intersubjetivas que possibilitam o desenvolvimento da autorrelação prática para Honneth ocorrem em três esferas distintas, cada uma correspondendo a uma forma diferente de reconhecimento: amor ou amizade nas relações primárias, direitos nas relações jurídicas e solidariedade e estima na comunidade de valores. Cada uma destas formas de reconhecimento 
está intimamente relacionada ao desenvolvimento de um tipo específico de autorrelação prática ou de relação consigo mesmo.

a) numa esfera que o autor define como íntima, a pessoa é reconhecida como um indivíduo com necessidades e desejos específicos. Nela o reconhecimento tem o caráter de uma devoção afetiva, incondicional, preocupada com o bem-estar do outro enquanto tal; essa devoção pode ser descrita com categorias como cuidado e amor. A autorrelação prática que se desenvolve aqui é a autoconfiança;

b) na segunda esfera, o indivíduo é reconhecido como uma pessoa a quem é atribuída a mesma capacidade moral que se atribui a todo ser humano. Nas sociedades modernas, essa esfera de reconhecimento é a das relações juridicamente mediadas e tem o caráter de um tratamento igualitário, universal pelo menos no âmbito da comunidade juridicamente definida. A autorrelação prática que os indivíduos desenvolvem aqui é designada de autorrespeito;

c) na terceira e última esfera, o indivíduo é reconhecido como uma pessoa cujas capacidades e habilidades são tidas como de valor para uma comunidade concreta. Em textos mais antigos Honneth denominou essa forma de reconhecimento como solidariedade; desde sua discussão com Nancy Fraser (Honneth, 2003b), ele se refere a ela como contribuição social ou realizações (Leistung; achievement). A autorrelação prática que os indivíduos desenvolvem nessa esfera é designada de autoestima (Honneth, 2007, p. 138-139).

Honneth (1992, p. 196) defende que essas três formas de reconhecimento constituem a infraestrutura moral e que elas devem estar presentes nas relações sociais cotidianas, no mundo social vivido, para que este esteja em condições de proteger seus membros. Se as três formas de reconhecimento estiverem presentes ali onde o indivíduo se relaciona cotidianamente, apoiando-o, então ele pode desenvolver ali autorrelações práticas saudáveis. A indicação destas três esferas e das formas correspondentes de reconhecimento, no entanto, não prescreve formas concretas de vida nem arranjos institucionais específicos para as relações sociais. Com isso, precisamente por enfatizar que a referência para sua teoria são as sociedades modernas, o autor quer colocar um quadro referencial para uma teoria social crítica capaz de abrigar a pluralidade dos projetos de vida e a diversidade das sociedades atuais.

Ainda que não seja tematizado explicitamente, as autorrelações práticas são concebidas como estágios cumulativos num processo de desenvolvimento. Tomando a psicologia social de Mead como base, Honneth (1992, p. 189) defende que "a individualização humana é um processo no qual o indivíduo 
pode desdobrar uma identidade prática na medida em que for capaz de assegurar-se do reconhecimento por um círculo crescente de parceiros em suas interações". Não se trata, como talvez inadvertidamente poderia ser suspeitado, de uma socialização; ao contrário: o que Honneth está tratando aqui é da formação do indivíduo capaz de exercer-se como sujeito autônomo. Nesse sentido o autor continua: "Sujeitos capazes de linguagem e ação são constituídos como indivíduos tão somente aprendendo, a partir da perspectiva dos outros que lhe oferecem aprovação, a relacionar-se consigo próprios como seres que possuem determinadas qualidades e habilidades positivas". Porque a pessoa depende tanto do reconhecimento dos outros para se tornar um sujeito capaz de exercer sua autonomia, todos os outros têm em relação a ela o dever moral de dispensar-lhe reconhecimento. Alcançar o estágio subsequente não implica que o anterior esteja ou devesse estar completo e definitivo; reconhecimento e a correspondente relação prática positiva consigo mesmo são concebidos pelo autor como processos de formação que duram a vida toda. Por conseguinte, para todos os participantes de relações sociais o reconhecimento é tanto uma necessidade (para si próprios) como um dever (para com os outros).

Na situação cotidiana das relações sociais pode ocorrer que o reconhecimento devido ou esperado não seja dispensado. Esses episódios podem ser consequências de uma interpretação incorreta da situação compartilhada, de constrangimentos ou de indiferença momentânea. Essas seriam situações que se pode designar como acidentais. Essas ocorrências devem ser distinguidas de negações sistemáticas ou deliberadas de reconhecimento. No projeto teórico de Honneth, a negação do reconhecimento, muitas vezes designada como desrespeito, é apresentada como injúria moral e como injustiça. A negação do reconhecimento é uma injuria moral por ser o descumprimento de uma obrigação moral; ela é uma atitude injusta não apenas porque constrange ou causa sofrimento aos indivíduos, mas em especial porque prejudica ou impede o desenvolvimento de autorrelações práticas salutares, porque impede a formação de uma identidade própria que dá sustentação à autonomia nos sujeitos. Referindo Mead, Honneth (1992, p. 189) afirma: "Uma vez que em sua imagem de si próprio [...] cada indivíduo depende da possibilidade de uma constante reafirmação pelo Outro, a experiência do desrespeito implica no risco de uma injúria que pode levar a um colapso da identidade da pessoa como um todo".

A cada uma das três formas de reconhecimento e das três formas de autorrelação prática acima descritas corresponde uma forma de desrespeito ou injúria moral que ameaça uma componente específica da identidade; 
a) a primeira diz respeito ao bem-estar físico e psicológico e é considerada a forma elementar de reconhecimento. Negligenciar ou negar o reconhecimento nas relações primárias destrói “a confiança no valor que as necessidades de cada um têm aos olhos dos outros". Para Honneth (2007, p. 136), "ao lado do assassinato, que desconsidera todas as formas de bem-estar físico, casos típicos desta classe são abuso físico, tortura e estupro".

b) a segunda forma de reconhecimento está relacionada com a responsabilidade moral; em sociedades modernas ela envolve direitos e deveres iguais para cada sujeito individualmente. Como formas típicas de desrespeito Honneth menciona um leque de lesões que vão do engano, da fraude e denegação de direitos em relações individuais até a discriminação de grupos inteiros de pessoas;

c) o reconhecimento da contribuição de capacidades, ações específicas e realizações de um indivíduo ou grupo é de importância constitutiva para o tipo de estima que eles receberão em sua comunidade; sua recusa implica em eles serem considerados insignificantes ou até mesmo indesejados dentro da comunidade. O autor (Honneth, 2003b) menciona gestos simples, como não saudar a outra pessoa, e bem mais sérios, como a estigmatização, como exemplos da negação de reconhecimento. Em sociedades capitalistas, a contribuição relacionada com o trabalho e sua interpretação são parte desta forma de reconhecimento - e são objeto de reiterado desrespeito.

Precisamente porque nesta perspectiva teórica se estabelece uma relação muito estreita entre formas diferenciadas e contínuas de reconhecimento e o desenvolvimento de formas específicas de relações práticas positivas do indivíduo consigo mesmo, o substrato de sua autonomia, as várias formas de desrespeito, de injúria, e a recusa de reconhecimento adquirem uma importância fundamental para a pesquisa e a teoria sociais. Pelo menos quando se adota uma perspectiva como a da Teoria Crítica.

Numa perspectiva teórica - e numa postura de vida - onde as relações sociais são concebidas unicamente como um meio para satisfazer interesses particulares, o desenvolvimento de sujeitos com capacidades só é necessário quando e na medida de sua utilidade em planos estratégicos. Para a Teoria Crítica, ao contrário, cada indivíduo é concebido como corresponsável pelo bem-estar dos outros membros de sua comunidade. Esta corresponsabilidade é definida como uma obrigação moral, universal. Nas palavras de Honneth (2007, p. 137): “moralidade é a quintessência das atitudes que devemos adotar mutuamente para assegurar, juntos, as condições necessárias para nossa 
integridade pessoal". Necessitarei voltar a essa imbricação ética ${ }^{2}$ das relações sociais; antes disso, porém, pretendo descrever brevemente alguns resultados da pesquisa empírica.

Com seu projeto teórico, Honneth tem a pretensão de desenvolver um marco referencial que torne possível detectar empiricamente experiências de injustiça tão precocemente quanto possível e ao mesmo tempo fornecer uma referência fundamentada para a crítica de situações concretas (cf. Honneth, 2003b). Na literatura sociológica e filosófica (Flickinger, 2003) frequentemente os movimentos sociais são descritos como agentes de alerta precoce, no sentido de que eles normalmente são mais sensíveis que as instituições especializadas para detectarem desajustes e são aptos a reagirem mais rapidamente.

Um argumento enfático de Honneth na defesa de sua construção teórica centrada no reconhecimento, no entanto, é que existem inúmeras experiências de sofrimento e injustiça feitas pelas pessoas em seu contidiano que (ainda) não são articuladas na esfera pública de modo a constituírem movimentos sociais. Movimentos sociais, segundo sua argumentação (Honneth, 2003b, p. 128), dependeriam muito de algum tipo de articulação das percepções; dentro deles "haveria insuficiente orientação anterior para que estivessem aptos a perceber qualquer estrato de orientação normativa". Nesse sentido, o marco referencial por ele desenvolvido deveria ser capaz de captar antecipadamente mesmo tais detecções sensitivas - ou pelo menos ser capaz de instrumentalizar os pesquisadores para tal. A tarefa da teoria social, então, é reconstruir as expectativas normativas que os membros daquela sociedade específica assumem. Essas expectativas devem ser assumidas porque "cada sociedade requer uma justificação na perspectiva de seus membros no sentido de que ela deve preencher um número de critérios normativos que surgem de reivindicações profundamente enraizadas no contexto de interações sociais" (ibid., p. 129). Esta é a razão pela qual, num marco teórico em que a intersubjetividade é escrita em negrito, mesmo os sentimentos de descontentamento e o sofrimento de indivíduos singulares são tidos como sociais; para Honneth, eles coincidem com a experiência de que a sociedade está fazendo ou permitindo que se faça algo injusto, algo injustificável.

\footnotetext{
${ }^{2}$ Em certos círculos da filosofia social é feita uma distinção entre moralidade (universal) e eticidade (contextualizada). Não seguirei essa distinção num sentido estrito, mesmo que seja impossível discutir aqui as razões para tanto. Mas vale lembrar que o significado pode ser exatamente o oposto: ética seria universal, ao passo que a moral definiria as obrigações locais (Dussel, 2000). Ao fazer referência direta a autores, será preservada a sua terminologia.
} 


\section{Procurando reconhecimento, encontrando desrespeito}

Tal como mencionado no início do texto, foi feita uma pesquisa em um contexto de pobreza e violência. O governo brasileiro havia financiado uma política específica para tais contextos, denominada Programa Nacional de Segurança Pública com Cidadania (Pronasci). O Pronasci combinava a repressão ao crime, em parte com equipamentos sofisticados como sistemas de detecção de tiro, com atividades de assistência social e educação. Áreas consideradas extremamente violentas na periferia das cidades foram o alvo específico dessa política.

Dentro de um conjunto de quase uma centena de medidas previstas no Pronasci, uma atividade estava voltada especificamente para mulheres e combinava assistência social e educação; chamava-se Mulheres da Paz (Ota, 2014). As participantes recebiam uma ajuda financeira mensal de $\mathrm{R} \$ 190,00$ e em troca se comprometiam a participar de cursos de formação e a ajudar a promover a paz em sua comunidade. Quatro destes grupos de mulheres foram acompanhados regularmente pelo grupo de pesquisa: observando os cursos, mantendo conversas informais com as participantes e com pessoas afins, fazendo grupos focais etc. Uma parte importante de nossa metodologia foi o convite a algumas mulheres participantes para contarem um pouco da história de suas vidas numa entrevista narrativa aberta. Depois de uma fala livre inicial, mais algumas perguntas eram feitas a partir de temas por elas mencionados. $\mathrm{Na}$ maioria dos casos seguiram-se mais uma ou duas entrevistas narrativas para aprofundar alguns tópicos. Algumas mulheres também foram convidadas a passar uma tarde na universidade, onde além de visitações participaram de um grupo focal.

Nosso ponto de partida era o interesse em uma política pública que combinava estratégias clássicas de repressão ao crime com determinadas formas de assistência social e a promoção de múltiplas dimensões da cidadania. Em certa medida, a expectativa era poder analisar especialmente como a segunda e a terceira forma de reconhecimento eram combinadas com a gramática da cidadania no contexto concreto de uma política pública. Mas desde o primeiro contato ficou claro que na vida cotidiana do grupo-alvo da política mencionada o sistema de relevância que orienta as expectativas normativas e os juízos cotidianos estava geralmente sobrecarregado e marcado por experiências de desrespeito e injúrias na esfera íntima. Justamente aquela esfera da vida social em que em tese se esperariam relações orientadas por afeto das pessoas mais próximas e uma devoção ao bem-estar, capazes de formar e continuamente informar uma relação de 
autorrespeito, era descrita como o epicentro de experiências de desrespeito e de sofrimento.

Um caso bastante típico com relação a essa sobrecarga com experiências de desrespeito e injúria nas mais diversas dimensões elementares da integridade físico-emotiva, mas dramático em sua densidade, será sumariado topicamente a seguir. Trata-se da história de vida de uma mulher que denominarei aqui de Infortunia. ${ }^{3}$ A entrevista toda durou 38 minutos, mas aqui serão referidos apenas partes dos 14 primeiros minutos de sua fala, um extrato da exposição a respeito de sua história pessoal. De acordo com nosso procedimento rotineiro, a entrevistadora Maria Eduarda Ota iniciou a pesquisa solicitando: "Fale-me um pouco sobre a história de sua vida". A resposta foi o seguinte relato sem as redundâncias e com algumas explicações entre colchetes feitas pela entrevistada no transcurso da entrevista.

Eu moro aqui na Bom Jesus há 39 anos. Nasci e me criei aqui.

Aos 15 anos de idade tomei um tiro... bala perdida.

E quando eu tinha uns 9 anos, eu sofri abuso, do meu cunhado [esposo da irmã].

E aos mesmos nove anos da minha filha, ele tentou abusar dela.

Daí eu acionei o conselho da criança e adolescente, acionei as outras instituições né... [...] Ela tem 22 anos e até agora não deu em nada [um pouco adiante ela retoma o tema: relata como em vão tentou proteger a filha, estuprada em outra tentativa, enquanto ela trabalhava].

E o meu filho com 6 anos de idade também foi abusado, por 6 guris da vila. Mas graças a Deus que a maioria tá morto [dois estão vivos; um foi atropelado, um se afogou, outro morreu de bala perdida e um está desaparecido].

E eu tenho muito medo das minhas crianças; meu guri grande, não deixo ele se misturar com ninguém. Ele fica sozinho em casa, melhor ficar em casa assistindo televisão e jogando videogame do que nas esquinas.

Meus irmãos cuidaram de mim. De nós, nós menores, que a minha mãe tinha que trabalhar; ela trabalhava dia e noite pra nos sustentar.

Minha mãe sofria muita violência em casa, meu pai batia nela. Meu pai batia em nós também quando nós era pequeno. Ele tanto bateu em mim, tanto bateu em mim, que... Agora quando ele morreu, morreu nos meus braços.

E é meio.. Ele pegava o prato de comida, jogava na cara da minha mãe, e dizia pra ela assim: "não quero essa porcaria aqui!"

E nós víamos tudo que acontecia na minha casa. A gente fazia que tava dormindo pra ele não bater em nós também.

\footnotetext{
${ }^{3}$ Do plural da palavra latina infortunium, e não de seu uso no senso comum.
} 
Um dia ele ia bater em mim e eu peguei um tijolo e joguei nele, mas errei, joguei pra errar mesmo.

E ai eu fui crescendo, crescendo e disse: não, agora eu vou casar e vou sair de casa. Foi quando eu resolvi morar com meu esposo e... ele tinha 39 anos e eu tinha 16 anos [aparentemente ele tinha 29 anos].

Ele quis né também... bater em mim. Mas chamei a lei Maria da Penha pra ele. Também não deu em nada, mas pelo menos ele parou quieto.

Ele nunca assim me agrediu, mas com palavras já, né... E uma palavra dói bem mais que um tapa na cara. Falar as coisas que a pessoa não fez, né...

Sempre trabalhei, sempre... Tudo que eu queria assim eu adquiri, eu adquiri com meu braço, com meu suor...

Eu estou trabalhando, mas eu assinei o aviso. Seis anos trabalhando no hospital, nunca faltei, nunca cheguei atrasada. ${ }^{4}$

Meu esposo faz, na segunda feira ele faz a cirurgia também. Tem que cuidar [dele] também. Agora ele tá mais calmo também... Tá mais tranquilo. Pra mim e pros meus filhos tá mais tranquilo.

$[\ldots]$

Eu vi meu irmão morrer dentro de casa guria... Um monte, um monte de tiro. E ele correndo dentro de casa, e os caras correndo tudo atrás dele. Deram tiro na cara dele, outro no abdomen dele, furaram ele à bala, todinho. Peneira, fizeram uma peneira dele. $O$ rosto dele tu não via né. Peneiraram ele, todinho.

E outra coisa: também aqui na vila, meus primos também foram assassinados... mataram todos eles. A menina e os três guri, os irmãos dela. Eles estavam na hora errada, na casa errada e no lugar errado. [Segue a explicação de como o irmão e os primos morreram: o irmão num latrocínio e os primos como vingança ambos mortos por traficantes.]

[...] o pai duma menina na vila, que mora na Restinga, pegaram ele, retalharam todinho ele, os braços, as pernas, tiraram os testículos dele, tiraram a cabeça dele, jogaram bola com a cabeça dele, botaram dentro dum buraco e tocaram fogo nele.

E a menina tá numa instituição pra adoção, a mãe não pode pegar a menina, porque senão ela também morre, e a menina está com 10 anos hoje [Aparentemente há uma vingança pendente, e a visita da mãe permitiria aos criminosos descobrirem onde a menina está].

É terrivel. Ai é até ruim de falar essas coisas... mas tem que se abrir né, tem que se abrir

[Ela volta a falar do seu estupro] A gente falava pra mãe [sobre os abusos] e a mamãe não acreditava.

Ele [o estuprador] cuidava sempre da gente, sempre; a minha mãe trabalhava. E ai é triste, né guria, é ruim, é terrivel. Imagina chegar

${ }^{4}$ Ela trabalhou seis anos na lavanderia de um hospital público através de uma empresa terceirizada; o contrato foi considerado ilegal, e todos foram despedidos. 
e falar pro pai isso aí, e pra mãe, é horrível. A minha mãe não acreditava em nós. E ai tudo isso fica remoendo a gente né, vai machucando, vai revoltando. E meu menino também, de 6 anos, ele é mais assim, problemático mentalmente por causa disso ai também, tenho certeza. Quando ele vai crescendo, não vai esquecer isso daí, jamais [Ela expressa seus temores sobre o futuro do filho].

Viu o que é minha vida? Isso que eu te contei só a história da minha vida, imagina se eu contar a do povo aí da vila né...

Quando perguntada sobre sua participação no projeto Mulheres da Paz, Infortunia começa a segunda parte da entrevista dizendo:

Ah guria, a gente acha que a gente tem problema né, mas tem gente com bem mais problemas que a gente. To achando bom, que dai a gente pode ajudar as pessoas, né? Que têm os mesmos problemas que a gente, só que a gente não vê os problemas deles. Mas um dia eles vão contar os problemas deles.

Contando sua história dessa maneira, Infortunia expressa ter consciência da injustiça, mesmo que ela não emoldura suas experiências num discurso ético. Há muitos acontecimentos dispersos ao longo de sua vida com os quais ela está em desacordo, que frustram suas expectativas sobre como as pessoas de seu relacionamento deveriam ter agido, e ela percebe isso como uma injúria. Chama a atenção que ao longo de todo o relato nenhuma das pessoas de seu círculo pessoal foi digna de ser associada por ela com alguma experiência positiva. Há silêncio sobre o cuidado afetivo na casa de sua família e mais tarde na sua própria, sobre amigas e amigos, sobre a escola. O único aspecto mencionado como um projeto de vida foi casar-se - para escapar da violência doméstica. E não foi uma experiência bem sucedida.

\section{A expectativa de uma luta por reconhecimento}

Em certa maneira, a história da vida de Infortunia confirma algumas hipóteses de Honneth (2007, cap. 4) expressas em uma palestra proferida em 1981, em Dubrovnik, sobre a dessimbolização e a individualização institucionalizada. O primeiro conceito tem a ver com a falta de meios linguísticos e simbólicos para expressar a consciência de injustiça num marco mais amplo e articulado. O segundo tem a ver com as formas de organização da vida social que dificultam muito ou mesmo impedem uma partilha eticamente informada das experiências cotidianas de injúria e injustiça. Vencer essas duas barreiras seria uma condição necessária, mesmo que não suficiente em si, para a formação de resistência coletiva, como por exemplo protestos ou um 
movimento social, e para recuperar consciência do contorno mais amplo do conflito social que é constitutivo da distribuição desigual das chances para conceber e realizar projetos próprios de vida, tanto em nível individual como de grupo.

A despeito de iniciativas em curso para proceder a pesquisas empíricas sobre as expectativas normativas, as percepções de desrespeito e injustiça e a questão da mobilização de resistências, ainda há um grande défice de parâmetros sociologicamente mensuráveis para identificar empiricamente o desenvolvimento de autorrelações práticas positivas nos termos pressupostos por Honneth (Pereira, 2014). Além disso, na sociologia há grande resistência para se fixar em discursos que estabelecem conexões causais; talvez tenhamos que nos contentar com concepções como a de Weber, de causalidade adequada como uma probabilidade de concomitância.

Mas as histórias de vida que ouvimos em pesquisas em contextos como o que aqui está sendo referido revelam uma cadeia de falhas nas relações sociais. A verbalização mais enfática diz respeito às múltiplas formas de desrespeito à integridade do corpo. Sinais ou indicadores de uma autoconfiança fragmentada acompanham essas verbalizações. A denegação de direitos e de assistência são também referidos constantemente. Assim não surpreende que o desemprego, baixos salários, jornadas extenuantes e pobreza, sinais evidentes de uma subvalorização social das capacidades, habilidades e do trabalho destes grupos sociais, estejam amplamente disseminados.

As verbalizações, no entanto, não são parte de uma interpretação comum da situação em que as pessoas afetadas vivem. Elas percebem com muita clareza que são afetadas por ações de terceiros que "não são certas", que contradizem expectativas normativas legítimas de respeito e reconhecimento. Mas no transcurso das entrevistas, e mesmo de conversas informais durante a observação a campo, a experiências de sofrimento não são articuladas num marco interpretativo mais amplo. Perceber, identificar, localizar no tempo, no espaço e sobretudo na sua dimensão social e poder verbalizar contextualizadamente acontecimentos que foram vivenciados pessoalmente, presenciados ou mesmo dos quais se teve notícia, para por fim poder estabelecer conexões com a própria biografia é uma atividade cognitivo-intelectual importante, indispensável até, para que o indivíduo possa se localizar no mundo. Com este processamento, os acontecimentos eles vão ganhando sentido como experiências e orientam as ações.

Na pesquisa, no entanto, frequentemente a descrição reiterada do mal sofrido não recebia um enquadramento referencial no contexto de suas biografias nem da vida de suas comunidades. A descrição, por conseguinte, tampouco era 
seguida de uma explicitação positiva do que as interlocutoras esperam como sendo o "dever" ético das pessoas com que estiveram relacionadas no tempo ou na situação a que se refere a narrativa. A capacidade de generalização que evidenciaria que essas práticas de desrespeito transcendem as relações individuais e estão enraizadas em hábitos ou estruturas muito mais amplas e profundas - e que necessitariam uma reação bem mais ampla que a indignação individual e silente -, se revelou ainda muito insipiente ou mesmo ausente nas pessoas entrevistadas.

O programa Pronasci intervinha de maneira muito ambígua nas regiões de sua implementação, mesmo naquelas dimensões que se poderia agrupar sob a designação de políticas sociais. Em sua faceta positiva, ele oferecia diversas oportunidades de formação e treinamento a grupos-alvo específicos como, no caso em pauta, a mulheres. Parte desta formação era o esclarecimento sobre direitos e sobre as instituições responsáveis por garanti-los. Também eram socializadas com e entre os participantes informações sobre as ofertas de políticas públicas, em especial as de assistência, e as possibilidades de acesso a elas.

Com isso, em tese, a política pública estaria servindo também como catalisador para a aquisição dos meios linguísticos e simbólicos que permitiriam às destinatárias criarem para si próprias o marco referencial no qual suas experiências de desrespeito e sofrimento e suas ainda insipientes percepções de injustiça pudessem ser articuladas, compartilhadas, transformadas em aprendizado coletivo. Uma política social assim, quando bem sucedida, levaria a que, ao lado do diagnóstico relativo a sua situação, as mulheres envolvidas se habilitariam a gradativamente fazerem prognósticos mais consistentes relativos às possibilidades de tomarem em suas mãos sua biografia, no sentido de construírem suas utopias concretas, e a encontrarem motivações para um protagonismo mais amplo relativo a suas próprias vidas.

A face menos visível, mas não menos importante, é que o Pronasci estava concebido como uma típica relação provedor-cliente, onde para cada questão específica existe uma instituição especializada a ser acessada. Nas diversas edições que o programa teve em Porto Alegre e região metropolitana, não havia qualquer coordenação entre os órgãos públicos envolvidos nem garantia de que as demandas seriam processadas dentro de um horizonte temporal razoável e compatível com a demanda. Ainda que as destinatárias fossem motivadas a acessarem os órgãos de proteção (delegacias, Conselho Tutelar etc.) e programas de políticas públicas (saúde, educação, cultura, assistência etc.), elas lá não eram recebidas como cidadãs, face às quais o estado, através de seus servidores públicos, tem uma obrigação de prestação de serviço. A interposição 
de barreiras e a indiferença eram uma queixa constante. As próprias atividades dentro do programa eram completamente desencontradas. ${ }^{5}$ As pessoas eram orientadas para que apresentassem suas demandas formalmente, mas não havia espaço formal para acolhê-las, não havia incentivo para que as instituições e os servidores públicos cumprissem com seu dever prestacional, nem havia espaço para uma reação agonística, para uma luta pelo reconhecimento.

O melancólico fim do Pronasci após a saída de seu idealizador do Ministério da Justiça expôs uma vez mais a descontinuidade das políticas públicas no Brasil. A apropriação simbólica ostensiva (Sobottka, 2006) de políticas públicas, fazendo com que o governante ou gestor de turno a apresente como um benefício que ele oferece pessoalmente à população, ainda que ela seja uma política pública, financiada com recursos públicos, reforça os laços provedor-cliente e pouco contribui para o reconhecimento das pessoas como cidadãs. No limite pode-se suspeitar que o Pronasci, tal como muitas políticas públicas, em especial as sociais, reforçam nos contextos suburbanos de extrema pobreza as experiências de desrespeito e de negação da cidadania. No período em que foi observado, nem o Pronasci como um todo, nem o programa Mulheres da Paz não conseguiu transformar-se em um suporte para que, individualmente ou em grupo, as participantes, em sua condição de cidadãs, pudessem encetar um processo de cura, ou pelo menos de rearranjo de suas biografias e suas autorrelações fragmentadas, que permitisse que elas mesmas se constituíssem em sujeitos ativos nas suas histórias de vida - se considerarmos que a esperança de virem a ser sujeitos ativos de suas histórias seja exagerada.

Feita esta análise dos resultados da pesquisa junto às mulheres participantes do programa Mulheres da Paz, é possível retornar à pergunta inicial: se a teoria do reconhecimento, como formulada por Axel Honneth, pode servir de referência para pesquisas em contextos distantes e distintos daquela sua origem e se se confirma a expectativa externada por ele de que o sofrimento devido a situações agudas de desrespeito teria um grande potencial para desencadear de lutas por reconhecimento.

\footnotetext{
${ }^{5}$ Para dar um só exemplo: as Mulheres da Paz deveriam mobilizar os jovens de suas comunidades para um programa específico para eles. Era uma espécie de extensão do papel de mãe que se preocupa em conduzir o jovem ao "bom caminho" e o afasta de riscos como o envolvimento com o mundo das drogas. As mulheres recebiam treinamento e uma ajuda mensal e, em contrapartida, tinham a obrigação de desempenhar este papel. Mas em nenhum dos lugares pesquisados o programa para os jovens iniciou antes do final do programa Mulheres da Paz, tornando impossível que cumprissem os termos do acordo feito - e impedindo que elas tivessem uma oportunidade a mais de aprendizado cidadão, percebendo a conexão interna entre os direitos e os deveres que o status de cidadania implica.
} 
Com relação à primeira parte da questão é preciso dizer que a teoria do reconhecimento nos forneceu um marco de referência para perceber, enquadrar e interpretar experiências cotidianas que eram narradas dispersamente e muitas vezes de forma muito desconexa. As narrativas sobre os acontecimentos vinham acompanhadas de avaliações de que o ocorrido "não era certo", e de fragmentos frasais ou gestos que expressavam um sofrimento nitidamente experimentado, mas parcamente verbalizado. Faltavam às protagonistas da narrativa os recursos simbólicos para tornar suas experiências produtivas - e a política pública envolvida antes reforçou que remediou esta carência. Ela segue uma longa tradição de apropriação simbólica, onde o governante transforma a política pública em uma ajuda que ele ou seu grupo político concedem e pela qual os destinatários lhe devem alguma reciprocidade (Sobottka, 2014a; 2014b). Nesta situação vivencial e política foi possível verificar que a teoria do reconhecimento pode sim ser operacionalizada e contribuir para as pesquisas empíricas em contextos bem distintos daquele que lhe serviu de referencial. Ela ajuda o pesquisador a formular e enquadrar questões que as protagonistas da narrativa não conseguiam articular nem enquadrar num contexto maior de relações sociais desiguais.

Há, no entanto, uma segunda faceta, bem mais complexa: a expectativa - quase sempre implícita, mas nítida - em Honneth de que o sofrimento e a percepção de ter sido injustiçado daria um impulso a iniciativas de superação desta situação. Na disputa com Nancy Fraser (Honneth, 2003b) ele coloca esta expectativa em termos de uma esfera pública e do surgimento de movimentos sociais como lugares sociais da reconquista do reconhecimento devido. Num nível mais filosófico, vinculado estreitamente a Hegel, ele coloca a eticidade como espaço social da libertação, do processo de cura (Honneth, 2007a, cap. II.4). Enquanto na primeira formulação haveria um engajamento mediado por uma coletividade, na segunda Honneth volta a divisar um protagonismo individual, quase kantiano. No contexto estudado, o cumprimento de nenhuma destas duas versões da expectativa pode ser constatada. O autor parece ter esquecido as consequências que a dessimbolização e a individualização institucionalizada, por ele próprio descritas (Honneth, 2007, cap. 4), têm como bloqueadoras de autorrelações práticas positivas. E sem elas, as dificuldades para protagonizar lutas por reconhecimento tornam-se muito grandes.

Angela R. Paiva (2015) considera que a organização social no Brasil seja ambivalente, esquizofrênica: extremamente desigual, porém harmoniosa; ela enumera a hierarquização na ordem social, a organicidade na concepção de mundo, o paternalismo nas relações sociais e o autoritarismo na esfera pública como entraves para o despertar de reações dos que permanecem à margem 
da formação de uma sociedade republicana e para a fruição universalizada da cidadania no Brasil. Com isso ela relaciona, focada na cidadania, efeitos desmobilizadores de longo prazo de uma ordem social desigual e excludente sobre a subjetividade daqueles que são subalternizados.

É bem provável que somente a combinação de políticas sociais emancipatórias (cf. Paiva, 2015) que rompam os ciclos de apropriação simbólica hoje tão comuns (Sobottka, 2014a), e um longo aprendizado em relações intersubjetivas como aquelas possibilitadas por resistência, mobilizações e movimentos sociais (Sobottka, 2015, p. 123ss), traria para o horizonte destas mulheres e de toda a sociedade em que estão inseridas, uma postura mais agonista e incentivaria desencadeamento de lutas por reconhecimento, que o sofrimento pelo desrespeito e a percepção de injustiça, por si sós, não são capazes de produzir.

\section{Referências}

DUSSEL, E. Ética da Libertação: na idade da globalização e da exclusão. Petrópolis: Vozes, 2000

FLICKINGER, H.-G. Em nome da liberdade: elementos da crítica ao liberalismo contemporâneo. Porto Alegre: Edipucrs, 2003.

HABERMAS, Jürgen. Theorie des kommunikativen Handelns. Frankfurt am Main: Suhrkamp, 1988. 2 v.

HONNETH Axel. Integrity and disrespect: principles of a conception of morality based on the theory of recognition. Political Theory, v. 20, n. 2, 1992, p. 187-201 $<10.1177 / 0090591792020002001>$.

HONNETH, Axel. Luta por Reconhecimento: a gramática moral dos conflitos sociais. São Paulo: Ed. 34, 2003 a.

HONNETH Axel. Redistribution as recognition: a response to Nancy Fraser. In: N. Fraser; A. Honneth. Redistribution or recognition? A political-philosophal exchange. London: Verso, 2003b. p. 110-197.

HONNETH Axel. Disrespect: the normative foundations of critical theory. Cambridge: Polity Press, 2007.

HONNETH, Axel. Sofrimento de indeterminação: uma reatualização da filosofia do direito de Hegel. São Paulo: Singular, 2007a.

HONNETH Axel. Das Recht der Freiheit: Grundriss einer demokratischen Sittlichkeit. Berlim: Suhrkamp, 2011.

HONNETH Axel. Barbarizações do conflito social: lutas por reconhecimento ao início do século 21. Civitas, v. 14, n. 1, $2014<10.15448 / 1984-7289.2014 .1 .16941>$.

OTA, Maria Eduarda. Gênero na Teoria Crítica e nas políticas públicas: a dicotomia público-privado em perspectiva. 2014. Dissertação (Mestrado em Ciências Sociais). Pucrs, Porto Alegre, 2014. 
PAIVA, Angela R. Cidadania, reconhecimento e ação afirmativa no ensino superior. Civitas, v. 15, n. 4, 2015.

PEREIRA, Gustavo. El espacio normativo de la autonomía como realización de la igualdad. Série Políticas Públicas, n. 191. Santiago: Cepal, 2014.

ROSENTHAL, Gabriele História de vida vivenciada e história de vida narrada: a interrelação entre experiência, recordar e narrar. Civitas, v. 14, n. 2, p. 227-249, 2014 $<10.15448 / 1984-7289.2014 .2 .17116>$.

SOBOTTKA, E. A. Por que se faz políticas sociais no Brasil? Notas sobre estratégias de legitimação nos últimos dois governos federais. Civitas, v. 6, n. 1, p. 79-93, 2006 $<10.15448 / 1984-7289.2006 .1 .23>$.

SOBOTTKA, E. A. A escola de Frankfurt nos anos 1930: sobre a teoria crítica de Max Horkheimer. In: A. M. Ribeiro et al. A modernidade como desafio teórico: ensaios sobre o pensamento social alemão. Porto Alegre: Edipucrs, 2008. p. 207-226.

SOBOTTKA, E. A. Trabalho e políticas sociais: reflexões sobre seu potencial emancipatório. In: Luiz Carlos Bombassaro; Claudio A. Dalbosco; Nadja Hermann (orgs.). Percursos hermenêuticos e políticos: homenagem a Hans-Georg Flickinger. Passo Fundo: Editora UPF, 2014a. p. 537-551.

SOBOTTKA, E. A. Pesquisar políticas de participação. In: Danilo R. Streck; Emil A. Sobottka; Edla Eggert (orgs.). Conhecer e transformar: pesquisa-ação e pesquisa participante em diálogo internacional. Curitiba: Editora CRV, 2014b. p. 85-94.

SOBOTTKA, E. A. Reconhecimento: novas abordagens em teoria crítica. São Paulo: Annablume, 2015.

Recebido em: 15 jul. 2015

Aprovado em: 1을. 2015

Autor correspondente:

Emil A. Sobottka

Av. Ipiranga, 6681, prédio 5 - Partenon

90619-900 Porto Alegre, RS, Brasil 